\title{
Allogeneic Hematopoietic Stem Cell Transplantation in Fanconi Anemia
}

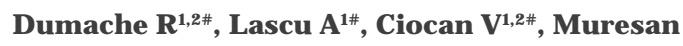 \\ $\mathrm{C}^{1,2 *}$, Mihailescu $\mathrm{A}^{1,3}$, Enache $\mathrm{A}^{1,2}$ and Arghirescu \\ $\mathrm{S}^{1,4}$ \\ ${ }^{1}$ Victor Babes University of Medicine and Pharmacy \\ Timisoara, Romania \\ ${ }^{2}$ Center for Ethics in Human Genetic Identification, Victor \\ Babes University of Medicine and Pharmacy Timisoara, \\ Romania \\ ${ }^{3}$ Genomics Research Center, Victor Babes University of \\ Medicine and Pharmacy Timisoara, Romania \\ ${ }^{4} 3^{\text {rd }}$ Pediatrics Clinic Victor Babes University of Medicine \\ and Pharmacy Timisoara, Romania \\ \#Contributed Equally to this Article
}

*Corresponding author: Muresan C, Department of Forensic Medicine, Bioethics, Deontology and Medical law-Victor Babes University of Medicine and Pharmacy Timisoara, Romania; $2^{\text {nd }}$ Eftimie Murgu Square, 30041, Timisoara, Romania

Received: June 01, 2021; Accepted: June 29, 2021; Published: J uly 06, 2021

\begin{abstract}
Objective: Allogeneic Hematopoietic Stem Cell Transplantation (HSCT) is the treatment of choice in patients with Fanconi Anemia (FA). The aim of our study is to evaluate the impact and benefits of allogenic matched donor HSCT in a case of a 12 year-old girl with FA, who displayed good clinical evolution following 2 months post-transplantation.
\end{abstract}

Patients and Methods: In the pre-transplant phase, reference blood samples from the donor and recipient were collected on EDTA. The DNA from blood samples was extracted using an automated Maxwell ${ }^{\circledR} 48$ RSC instrument (Promega, USA) with the Maxwell ${ }^{\circledast}$ RSC Whole blood DNA kit (Promega, USA). For DNA quantification, the PowerQuant System kit (Promega, USA) was used with the ABI 7500 Real-time PCR system (Applied Biosystems, USA). The amplification of the short tandem repeat markers was performed using the 24plex Investigator QS kit (Qiagen, Germany) on a ProFlex PCR System. Furthermore, the PCR products were separated and detected on an ABI 3500 Genetic Analyzer (Applied Biosytems, USA).

Results: After 30 days of the transplantation, a Complete Chimerism (CC) was achieved with a full replacement by donor derived hematopoietic cells. After 60 days of the transplantation, the $\mathrm{CC}$ status was maintained with improvement of hematological findings.

Conclusion: In FA, chimerism monitoring after HSCT provides useful informations of engraftment or possibility of post-transplantation complications such as graft versus host disease.

Keywords: Fanconi Anemia (FA); Hematopoietic Stem Cell Transplantation (HSCT); Short Tandem Repeat (STR); Chimerism

\section{Introduction}

Fanconi Anemia (FA) is a rare genetic disorder, and most common congenital hematopoietic disorder presenting with bone marrow failure syndrome and increased cancer susceptibility. The disease was first documented in 1927 by the swiss physician Giulio Fanconi. The disease is caused by impaired ability to repair Deoxyribo Nucleic Acid (DNA) damage, and thus is characterized by chromosomal instability and hypersensitivity to DNA interstrand cross-linking agents such as mitomycin C [1]. The phenotype is determined by genetic mutations in at least 30 different genes. Some specific populations present founder mutations with increased carrier frequencies, including Askenazi Jewish (FANCC, BRCA2/FANCD1), northern Europeans (FANCC), Afrikaners (FANCA), Spanish Gypsies (FANCA) and others [2]. The disease usually begins with abnormal blood findings including cytopenias in childhood, but in later life, it commonly develops serious hematologic disorders including Myelodysplastic Syndrome (MDS) or hematologic malignancies such as acute myeloid leukemia (AML) [3]. Diagnosis is established in a proband who presents with increased chromosome breakage or radial forms on cytogenetic testing of lymphocytes by diepoxybutane or mitomycin C. The diagnosis can be established before or after birth, even in cases with aplastic anemia or leukemia that may or may not have the typical signs associated with the disease [4]. Because the disease is a genetic disorder, replacement with new and healthy blood cells through Hematopoietic Stem Cell Transplantation (HSCT) is fundamentally the only curative measure [5]. It is important to estimate the success or failure of procedure and to predict recurrence of the disease after the HSCT. In that regard, evaluation of chimerism is useful measure and has been widely used after HSCT [6]. Here, we report the outcome of complete chimerism in a matched sibling donor HSCT of a 12-year-old girl.

\section{Patients and Methods}

In June 2018, a 12-year-old girl was admitted to the Clinic of Oncohematology Timisoara due to multiple spots of hypopigmentation distributed throughout her body (head, torso, lower and upper extremities). Also, a hypocromic spot of $1.5 \mathrm{~cm}$ was observed on her posterior torso. The laboratory analysis at the admission presented the following values: hemoglobin $7.8 \mathrm{~g} / \mathrm{dL}$; thrombocytes $21 \times 10^{3} /$ $\mathrm{mm}^{3}$, leukocytes $2.44 \times 10^{3} / \mathrm{mm}^{3}$, neutrophils $25.8 \%$. The bone marrow cytology presented hypoplasia on 2 cellular lineages. She was diagnosed with Fanconi anemia. Therefore, HSCT was the only therapeutic option for cure. She was matched to a blood-related donor, younger sister. Prior to the transplantation, she was HLA-typed for HLA-A, -B, -C, DRB1, and DQB1 using high resolution typing. Prior to the HCST, blood samples collected on anticoagulant EDTA were received from both the donor and the recipient to establish reference 
genetic profiles in the Laboratory of Forensic Genetics of Victor Babes University of Medicine and Pharmacy Timisoara, Romania.

\section{DNA extraction from the biological samples}

Prior to the allogenic HCST, peripheral blood samples collected on anticoagulant EDTA was received from both the donor and the recipient in the Laboratory of Forensic Genetics of Victor Babes University of Medicine and Pharmacy Timisoara, Romania. The DNA extraction was performed on the automate Maxwell 48 RSC instrument (Promega, USA) using the Maxwell RSC Whole blood DNA kit (Promega, USA) for the blood samples. We performed the DNA extraction according to manufacturer recommendations.

\section{Quantification of the extracted DNA samples}

For DNA quantification of the donor and the recipient samples, the PowerQuant System kit (Promega, USA) was used. We prepared for each sample according to manufacturer recommendations, preparing the mixed solution with a final volume of $18 \mu \mathrm{L}$, consisting of $10 \mu \mathrm{L}$ of PowerQuant $2 \times$ Master Mix; $7 \mu \mathrm{L}$ of Amplification grade water, and $1 \mu \mathrm{L}$ of PowerQuant $20 \mathrm{x}$ PrimerMix. The quantification was performed on a 7500 real time PCR system (Applied Biosystems, USA), using the HID Real-Time PCR Analysis Software v2.0.6. Final concentrations of DNA were $20.18 \mathrm{ng} / \mu \mathrm{L}$ in donor blood, and $34.05 \mathrm{ng} / \mu \mathrm{L}$ in recipient.

\section{Amplification of the DNA samples}

The DNA samples from the donor and the recipient were amplified for the STR markers using the Investigator 24plex QS kit (Qiagen, Germany). The analysis was done following recommendations of the manufacturers. The DNA samples' amplification was performed on a ProFlex PCR System (Applied Biosystems, USA). PCR of the blood DNA samples was carried out in a total volume of $25 \mu \mathrm{L}$. The final volume of the reaction contained: $7.5 \mu \mathrm{L}$ of Fast Reaction Mix $2.0 \mu \mathrm{L}, 2.5 \mu \mathrm{L}$ of Primer Mix, $12.5 \mu \mathrm{L}$ of nuclease-free water, and $2.5 \mu \mathrm{L}$ of template DNA. The Investigator 24plex QS Kit (Qiagen, Germany) contains 22 autosomal STR markers as follows: D1S1656, D2S441, D2S1338, D3S1358, D5S818, D7S820, D8S1179, D10S1248, D12S391, D13S317, D16S539, D18S51, D19S433, D21S11, D22S1045, CSF1PO, FGA, TH01, TPOX, vWA, SE33, , DYS391, and the gender-specific marker Amelogenin. The conditions for the PCR amplification were as follows:

- 3 PCR cycles: temperature (T) $-98^{\circ} \mathrm{C}$ for 30 seconds; $\mathrm{T}=64^{\circ} \mathrm{C}$ for 55 seconds; $\mathrm{T}=72^{\circ} \mathrm{C}$ for 5 seconds.

27 PCR cycles: $\mathrm{T}=96^{\circ} \mathrm{C}$ for 10 seconds; $\mathrm{T}=61^{\circ} \mathrm{C}$ for 55 seconds; $\mathrm{T}=72^{\circ} \mathrm{C}$ for 5 seconds. After the $30 \mathrm{PCR}$ cycles were completed, a final extension (hold) at $\mathrm{T}^{\circ}=68^{\circ} \mathrm{C}$ was performed for 2 minutes followed by a final indefinite hold at $\mathrm{T}^{\circ}=10^{\circ} \mathrm{C}$.

\section{Capillary electrophoresis of the amplified DNA samples}

Samples were analyzed on a 3500 Genetic Analyzer following the manufacturer's recommendations. As autosomal STR markers, we used $1 \mu \mathrm{L}$ of the amplified PCR product (DNA sample) and $1 \mu \mathrm{L}$ of the Allelic Ladder $(\mathrm{AL})$. They were added into the mix containing $12.5 \mu \mathrm{L}$ of Hi-Di Formamide (Applied Biosystems, USA) and 0.5 $\mu \mathrm{L}$ DNA size standard BTO (Qiagen, Germany). Gene Mapper ID-X Software version 1.4 (Applied Biosystems, USA) was used to analyze the obtained data. For the statistical calculation, we used the Genoproof-3
Chimerism testing (Qualitype, Germany).

\section{Results}

Using capillary electrophoresis, we obtained the electropherograms and the genotypes of the donor and the recipient (Table 1). Thirty days after the HSCT, a new blood sample and electropherogram were collected from the recipient. The donor's genetic profile was present on the new electropherogram, indicating a complete chimerism. After 60 days, post-transplantation, complete chimerism was maintained (Table 1). The patient was released from the hospital on 71-day after the HCST, with the following results of blood parameters: hemoglobin $11.2 \mathrm{~g} / \mathrm{dL}$; red blood cells $3.81 \times 10^{6} / \mathrm{mm}^{3}$; thrombocytes $102 \times 10^{3} / \mathrm{mm}^{3}$; leukocytes $7.09 \times 10^{3} / \mathrm{mm}^{3}$; lymphocytes $53.64 \%$; monocytes $15.24 \%$; granulocytes $29.54 \%$; eosinophils: $1.64 \%$ and basophils: $0.10 \%$.

\section{Discussion}

The treatment of FA has improved with various treatment strategies in HSCT [5]. Since new cytoreductive treatments including fludarabine $[7,8]$ and T-cell depleted graft $[9,10]$ have been introduced, survival rates in FA after HSCT have increased. However, although HSCT aids in restoring hematopoiesis in patients, the HSCT itself are accompanied by many risks especially in FA. The defective ability of DNA repair in FA may make the patients more susceptible

Table 1: Monitoring of genetic chimerism through STR markers on pre-HSCT, 30- and 60-day after HSCT. Bold line indicates complete chimerism in the postHSCT period.

\begin{tabular}{|c|c|c|c|c|}
\hline \multirow{2}{*}{ STR markers } & \multicolumn{4}{|c|}{ Alleles } \\
\cline { 2 - 5 } & Donor & $\begin{array}{c}\text { Recipient } \\
\text { (pre-HSCT) }\end{array}$ & $\begin{array}{c}\text { Recipient } \\
\text { (30 days) }\end{array}$ & $\begin{array}{c}\text { Recipient } \\
\text { (60 days) }\end{array}$ \\
\hline THO1 & $6 ; 7$ & $6 ; 7$ & $6 ; 7$ & $6 ; 7$ \\
\hline D3S1358 & $15 ; 17$ & $15 ; 18$ & $15 ; 17$ & $15 ; 17$ \\
\hline vWA & $15 ; 18$ & $15 ; 18$ & $15 ; 18$ & $15 ; 18$ \\
\hline D2S11 & $29 ; 29$ & $28 ; 29$ & $29 ; 29$ & $29 ; 29$ \\
\hline TPOX & $8 ; 11$ & $8 ; 11$ & $8 ; 11$ & $8 ; 11$ \\
\hline DYS391 & - & - & - & - \\
\hline D1S1656 & $16 ; 17.3$ & $15 ; 16.3$ & $16 ; 17.3$ & $16 ; 17.3$ \\
\hline D12S391 & $18 ; 19$ & $18 ; 19$ & $18 ; 19$ & $18 ; 19$ \\
\hline SE33 & $22.2 ; 27.2$ & $18 ; 30.2$ & $22.2 ; 27.2$ & $22.2 ; 27.2$ \\
\hline D10S1248 & $13 ; 14$ & $13 ; 14$ & $13 ; 14$ & $13 ; 14$ \\
\hline D22S1338 & $16 ; 17$ & $15 ; 16$ & $16 ; 17$ & $16 ; 17$ \\
\hline D19S433 & $15 ; 15.2$ & $14 ; 15$ & $15 ; 15.2$ & $15 ; 15.2$ \\
\hline D8S1179 & $13 ; 14$ & $13 ; 15$ & $13 ; 14$ & $13 ; 14$ \\
\hline D2S1338 & $16 ; 17$ & $16 ; 17$ & $16 ; 17$ & $16 ; 17$ \\
\hline D2S441 & $11.3 ; 11.3$ & $17 ; 23$ & $11.3 ; 11.3$ & $11.3 ; 11.3$ \\
\hline D18S51 & $15 ; 21$ & $13 ; 15$ & $15 ; 21$ & $15 ; 21$ \\
\hline FGA & $20 ; 21$ & $20 ; 21$ & $20 ; 21$ & $20 ; 21$ \\
\hline D16S539 & $11 ; 12$ & $11 ; 12$ & $11 ; 12$ & $11 ; 12$ \\
\hline CSF1PO & $10 ; 12$ & $10 ; 12$ & $10 ; 12$ & $10 ; 12$ \\
\hline D13S317 & $8 ; 12$ & $8 ; 12$ & $8 ; 12$ & $8 ; 12$ \\
\hline D5S818 & $11 ; 12$ & $11 ; 11$ & $11 ; 12$ & $11 ; 12$ \\
\hline D7S820 & $8 ; 9$ & $9 ; 10$ & $8 ; 9$ & $8 ; 9$ \\
\hline & $\times X$ & $\times X$ & $\times X$ & $\times X$ \\
\hline
\end{tabular}


to chemotherapeutic agent or irradiation, and increase the risk of acute or chronic Graft-Versus-Host Disease (GVHD) and following tumors such as oral squamous cell carcinoma [11-13].

Chimerism analysis as a post-transplantation monitoring is a well-established measure. Among them, a measurement of Short Tandem Repeats (STR) using Polymerase Chain Reaction (PCR) is a most sensitive and a standard method to estimate the chimerism in HSCT [14]. Monitoring the chimeric status of patients following bone marrow transplantation is very important in establishing post-transplantation plan. Many physicians predict graft failure or disease recurrence after allogenic HSCT by checking chimeric status even prior to any detectable morphologic recurrence [6]. Complete chimerism (CC) indicates that impaired bone marrow cells are fully replaced with healthy donor's cells, which has been accepted as the ultimate goal in early and late stage of HSCT. However, the CC status has been also known to be associated with a higher risk of GVHD [15] after HSCT. In addition, recent strategy with reduced-intensity regimens to avoid post-transplantation complication increases the rate of Mixed Chimerism (MC) in HSCT. Some studies demonstrated that $\mathrm{MC}$ was also considered acceptable as a tolerant and disease-free status, especially in non-malignant hematopoietic diseases [16,17] Nonetheless, most studies have still demonstrated that the CC was associated with the higher survival rate than the MC [15]. Eventually, it is necessary to determine the reasonable goal of chimerism and the treatment protocols with appropriate intensity to achieve a balance between graft success and GVHD or post-transplantation tumor in non-malignant hematologic diseases [18].

Our patient showed complete chimerism on 30-day after HSCT and maintained complete status until 60-day, meaning that she was in complete clinical and morphological remission. Nonetheless, a patient like her who received a matched sibling-donor HSCT with reaching early CC should be carefully monitored whether to develop acute or chronic GVHD and other following complications during post-transplantation follow-up $[19,20]$. Finally, given recent success of gene therapy in trials to treat genetic disorders such as adrenoleukodystrophy, Wiskott-Aldrich syndrome, and metachromatic leukodystrophy, it is possible that gene therapy will emerge as a new treatment modality for with FA. This possibility is further supported by the recent development of refinements in HSC culture and transduction for FA [21].

\section{Conclusions}

In FA, the monitoring of chimerism after HSCT provides useful informations such as graft failure and possibility of GVHD. The CC status indicates successful engraftment and the better prognosis than the MC, while it is associated with post-transplantation complications including acute or chronic GVHD. Therefore, it is important to predict graft failure or post-transplantation complication, and to prepare possible therapeutic options through chimerism analysis. Above all, we expect that further study would determine the proper goal of chimerism and develop treatment protocol to avoid both graft failure and post-transplantation complication in non-malignant hematopoietic diseases such as FA.

\section{Acknowledgments}

We thank the patients for giving their permission to present this case report.

\section{References}

1. Key $Y$, D'Andrea AD. Molecular pathogenesis and clinical management of Fanconi anemia. J Clin Invest. 2012; 122: 3799-3806.

2. Kottemann MC, Smogorzewska A. Fanconi anemia and the repair of Watson and Crick DNA crosslinks. Nature. 2013; 493: 356-363.

3. Butturini A, Gale RP, Verlander PC, Adler-Brecher B, Gillio AP, Auerbach AD. Hematologic abnormalities in Fanconi anemia: an International Fanconi Anemia Registry study. Blood. 1994; 84: 1650-1655.

4. Auerbach AD. Fanconi anaemia and its diagnosis. Mutation Research. 2009; 668: 4-10.

5. Ebens CL, MacMillan ML, Wagner JE. Hematopoietic cell transplantation in Fanconi anemia: current evidence, challenges and recommendations. Expert Rev Hematol. 2017; 10: 81-97.

6. Zimmerman C, Shenoy S. Chimerism in the realm of hematopoietic stem cell transplantation for non-malignant disorders-a perspective. Front Immunol. 2020; 11: 1791.

7. Aker M, Varadi G, Slavin S, Nagler A. Fludarabine-based protocol for human umbilical cord blood transplantation in children with Fanconi anemia. J Pediatr Hematol Oncol. 1999; 21: 237-239.

8. Tan PL, Wagner JE, Auerbach AD, Defor TE, Slungaard A, Macmillan ML. Successful engraftment without radiation after fludarabine-based regimen in Fanconi anemia patients undergoing genotypically identical donor hematopoietic cell transplantation. Pediatr Blood Cancer. 2006; 46: 630-636.

9. Hertenstein B, Arseniev L, Novotny J, Ganser A. A comparative review of methods for $\mathrm{T}$ cell depletion in the prophylaxis of graft-versus-host disease. BioDrugs. 1998; 9: 105-123.

10. Chaleff S, Otto M, Barfield RC, Leimig T, lyengar R, Martin J, et al. A largescale method for the selective depletion of alphabeta $T$ lymphocytes from PBSC for allogeneic transplantation. Cytotherapy. 2007; 9: 746-754.

11. Khan FM, Sy S, Louie P, Ugarte-Torres A, Berka N, Sinclair GD, et al. Genomic instability after allogeneic hematopoietic cell transplantation is frequent in oral mucosa, particularly in patients with a history of chronic graftversus-host disease, and rare in nasal mucosa. Blood. 2010; 116: 1803-1806.

12. Deeg HJ, Socié G, Schoch G, Henry-Amar M, Witherspoon RP, Devergie A, et al. Malignancies after marrow transplantation for aplastic anemia and fanconi anemia: a joint Seattle and Paris analysis of results in 700 patients. Blood. 1996; 87: 386-392.

13. Yabe M, Morio T, Tabuchi K, Tomizawa D, Hasegawa D, Ishida H, et al. Longterm outcome in patients with Fanconi anemia who received hematopoietic stem cell transplantation: a retrospective nationwide analysis. Int J Hematol. 2021; 113: 134-144.

14. Dumache R, Enache A, Barbarii L, Constantinescu C, Pascalau A, Jinca $C$, et al. Chimerism Monitoring by Short Tandem Repeat (STR) Markers in Allogeneic Stem Cell Transplantation. Clin Lab. 2018; 64: 1535-1543.

15. Faraci M, Bagnasco F, Leoni M, Giardino S, Terranova P, Subissi L, et al. Evaluation of Chimerism Dynamics after Allogeneic Hematopoietic Stem Cell Transplantation in Children with Nonmalignant Diseases. Biol Blood Marrow Transplant 2018; 24: 1088-1093.

16. Park M, Koh KN, Seo JJ, Im HJ. Clinical implications of chimerism after allogeneic hematopoietic stem cell transplantation in children with nonmalignant diseases. Korean J Hematol. 2011; 46: 258-264.

17. Lejman M, Zawitkowska J, Zaucha-Prażmo A, Cienkusz M, Mroczkowska A, Kowalczyk J, et al. Influence of mixed chimerism on outcome in children with anaemia after haematopoietic stem cell transplantation. In Vivo. 2019; 33: 2051-2057.

18. Tuysuz G, Guler E, Ozel D, Kupesiz A. Results of Allogenic Hematopoietic Stem Cell Transplantation in Fanconi Anemia Caused by Bone Marrow Failure: Single-Regimen, Single-Center Experience of 14 Years. Biol Blood Marrow Transplant. 2019; 25: 2017-2023. 
19. Remberger M, Afram G, Sundin M, Uhlin M, LeBlanc K, Björklund A, et al. High incidence of severe chronic GvHD after HSCT with sibling donors. A single center analysis. Bone Marrow Transplant. 2016; 51: 1518-1521.

20. Peffault de Latour R, Porcher R, Dalle JH, Aljurf M, Korthof ET, Svahn J, et al; FA Committee of the Severe Aplastic Anemia Working Party; Pediatric Working Party of the European Group for Blood and Marrow Transplantation.
Allogeneic hematopoietic stem cell transplantation in Fanconi anemia: the European Group for Blood and Marrow Transplantation experience. Blood. 2013; 122: 4279-4286.

21. Verhoeyen E, Roman-Rodriguez FJ, Cosset FL, Levy C, Rio P. Gene Therapy in Fanconi Anemia: A Matter of Time, Safety and Gene Transfer Tool Efficiency. Curr Gene Ther. 2017; 16: 297-308. 